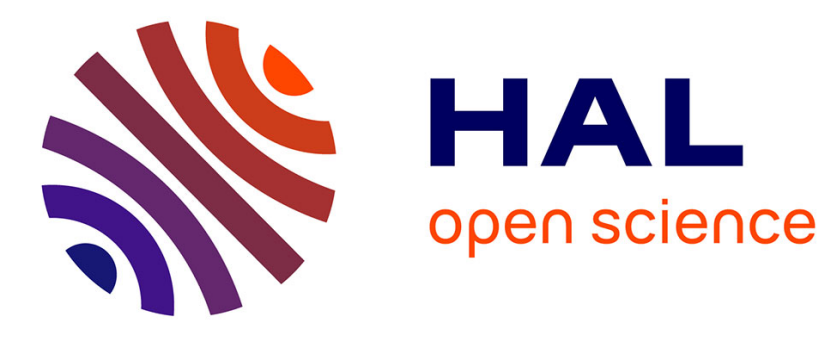

\title{
Water recovery from dew
}

Vadim Nikolayev, D Beysens, A Gioda, I Milimouk, E Katiushin, J.-P Morel

\section{To cite this version:}

Vadim Nikolayev, D Beysens, A Gioda, I Milimouk, E Katiushin, et al.. Water recovery from dew. Journal of Hydrology, 1996, 10.1016/0022-1694(95)02939-7 . hal-01264194

\section{HAL Id: hal-01264194 \\ https://hal.science/hal-01264194}

Submitted on 28 Jan 2016

HAL is a multi-disciplinary open access archive for the deposit and dissemination of scientific research documents, whether they are published or not. The documents may come from teaching and research institutions in France or abroad, or from public or private research centers.
L'archive ouverte pluridisciplinaire HAL, est destinée au dépôt et à la diffusion de documents scientifiques de niveau recherche, publiés ou non, émanant des établissements d'enseignement et de recherche français ou étrangers, des laboratoires publics ou privés.

\section{(a)(1) $\$$}

Distributed under a Creative Commons Attribution - NonCommercial - NoDerivatives| 4.0 
Published in: J. Hydrology 182 (1996) 19-35

\title{
Water recovery from dew
}

\author{
V. S. Nikolayev ${ }^{(1,5)}$, D. Beysens ${ }^{(1)}$, A. $\operatorname{Gioda}^{(2)}$, I. Milimouk $^{(1)}$, \\ E. Katiushin ${ }^{(3)}$, J.-P. Morel ${ }^{(4)}$, \\ (1) Service de Physique de l'Etat Condensé du Commissariat à l'Energie Atomique, Centre d'Etudes de \\ Saclay, F-91191 Gif-sur-Yvette Cedex (France) \\ (2) ORSTOM - BP 5045, F-34032 Montpellier Cedex (France) \\ (3) Museum for Regional Study of Feodosia, 11, Lenin Avenue, 334800, Feodosia (Ukraine) \\ (4) Centre National de la Recherche Scientifique, URA 284, Université de Provence, F-13621 \\ Aix-en-Provence (France) \\ (5) Permanent address: Bogolyubov Institute for Theoretical Physics, National Ukrainian Academy of \\ Sciences, 252143, Kiev, Ukraine
}

June 26, 1995

\begin{abstract}
The recovery of clean water from dew has remained a longstanding challenge in many places all around the world. It is currently believed that the ancient Greeks succeeded in recovering atmospheric water vapour on a scale large enough to supply water to the city of Theodosia (presently Feodosia, Crimea, Ukraine). Several attempts were made in the early 20th Cent. to build artificial dew-catching constructions which were subsequently abandoned because of their low yield. The idea of dew collection is revised in the light of recent investigations of the basic physical phenomena involved in the formation of dew. A model for calculating condensation rates on real dew condensers is proposed. Some suggestions for the "ideal" condenser are formulated.
\end{abstract}




\section{Introduction}

Atmospheric humidity can in principle be an alternative source of potable water in the arid and semi-arid zones. Condensation of the atmospheric vapour into water occurs in nature near the ground surface in two different forms: fog and dew. Fog is a cloud of already condensed water droplets. A high relative humidity (in practice 100\%) is necessary for the formation of fog. Water collection from fog is a resource in the arid zones where dense fog is frequent. Fog water collection by trees (Gioda et al., 1992) or by synthetic nets is very useful in the low mountain regions close to the ocean. Nowadays, it represents a non-negligible resource especially in Chile and Peru (Schemenauer and Cereceda, 1991; Bouloc, 1993; Gioda et al. 1993a, b).

The formation of dew requires a cold surface, but $100 \%$ humidity is not necessary. Thus, dew is common even in the dryer zones of the world. In contrast, fog is rare except in very particular locations like mountainous and coastal areas. This is why the idea of the recovery of dew water by collecting the water condensing on walls of special devices is so attractive.

\section{Historical sketch}

The history of the devices mentioned began in Feodosia, city of the Crimean peninsula in Ukraine. There is an old myth in Science that the Early Greeks who founded Theodosia (Greek name for the present Feodosia) about 6th Cent. B. C. used dew condensers to fulfil their water needs (Hitier, 1925; Jumikis, 1965; Gioda and Acosta Baladón, 1991). This belief comes from the Russian forester F. I. Zibold who was in charge of a countryside around Feodosia. To prove his theory he built an experimental condenser following what he considered to be an Early Greek condenser (Zibold, 1905, 1907; Hitier, 1925). Because of the importance of this pioneer's research we have investigated carefully the original manuscripts and other related documents as well as the remains of Zibold's construction.

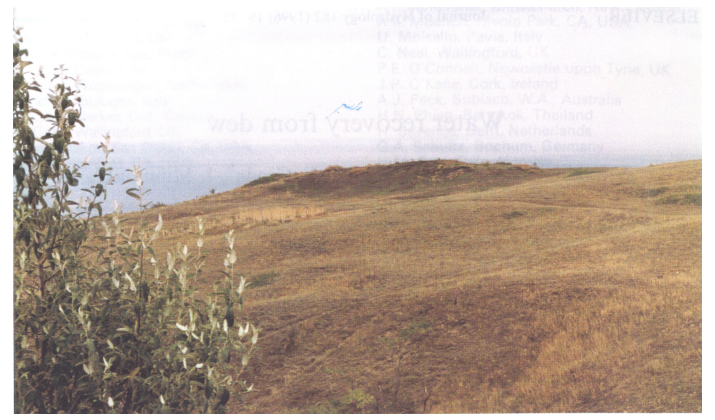

Figure 1: Present state of a tumulus which was thought to be an Early Greek condenser. It is situated on the hills of Tepe-Oba near the old Jewish Cemetery.

Zibold (1905) mentioned that "the climate in Feodosia is quite dry, the rains are rare and the droughts during several months are usual". From the Feodosia weather station data, the average annual rainfall is $366 \mathrm{~mm}$ and the average number of days with fog during a year is 25 . At the same time the conditions suitable for dew formation exist there as masses of humid air, which move from the sea in the evening, rise over the surrounding hills, the so-called Mount Tepe-Oba — c. $300 \mathrm{~m}$ a.s.l. — (Totchilov, 1938). While uprising, this humid air cools down and condensation can occur. Zibold mentioned a large quantity of dew but was unable to find any natural water sources in Feodosian forest. The existence of the ancient water supply which is functioning even now (Beysens et al., 1995) whose source remains unknown (Anonymous, 1935) led him to query the purpose of the numerous mounds on Tepe-Oba (Fig. 1). Zibold (1907) excavated around some of them and reported the remains of the ancient pipes and water channels. Finally, he concluded that the mounds were condensers of dew made by Early Greeks. However, at least several of the piles are actually tumuli without any signs of hydraulic purpose including a water supply system (Anonymous, 1935).

Based on the results of the archaeological excavations (Katiushin, 1979), one of us (E.K.) suggested that the chain of mounds described by Zibold is a part of the necropolis of antic Theodosia. Since the 1850s more than 80 mounds in the surroundings of Feodosia have been excavated (Beysens et al., 1995); 

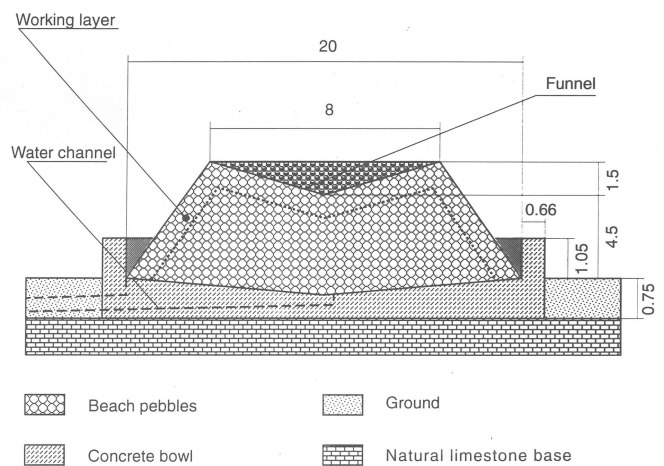

Figure 2: Section of the condenser of F.I.Zibold (initial state). The slope of the bowl is enlarged for the illustrative purpose. All the dimensions are given in meters. We have shown the working layer of the condenser by the dotted line.

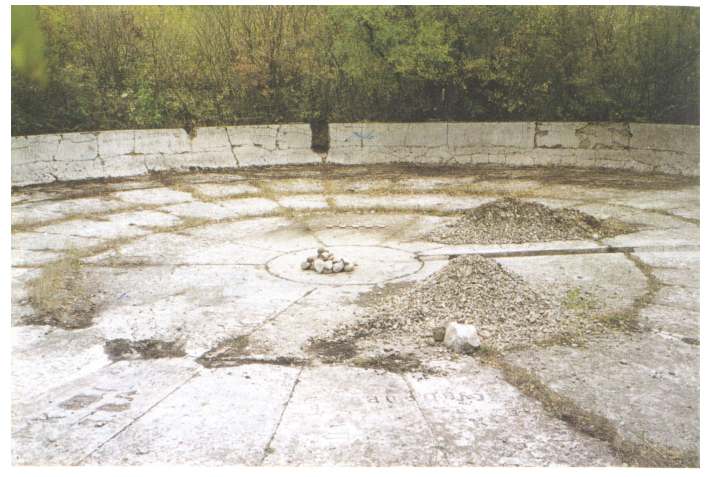

Figure 3: The present state of the remnants of the Zibold condenser.

they turned out to be the tombs either of ancient Greeks or Scythes and then dated to 4th-3rd Cent. B.C. These excavations revealed neither tubes nor water channels under the mounds.

While the mounds belong to 4th-3rd Cent. B.C., most of the water supply tubes which were found on Tepe-Oba and in Feodosia were laid out during the Middle-Ages when Feodosia became a Genoa city called Caffa. Hence, it is unlikely that the mounds and these tubes could function in the same water supply system. Meanwhile, it is possible that Italian inhabitants from Genoa replaced the tubes of the Early Greeks.

To prove that dew can be a source of water, Zibold built a model condenser, a huge truncated cone of sea-beach pebbles with a funnel on the top. It was mounted on a concrete bowl (Fig. 3) with a channel to let condensed water out. The structure was ready by the beginning of 1912 and was said by one Jacob Mironovitch Nikitas, a meteorologist of Zibold's forestry to yield up to 300-360 liters of water per day (Zhukov, 1931; Anonymous, 1935). Unexpectedly, the condenser stopped functioning. A leakage of the bowl was suspected (Anonymous, 1915) and then the cone of pebbles was demolished. However, the bowl is still visible (Fig. 3). Topological measurements (Beysens, 1993) show that the slope between the perimeter and the center of the bowl is now half that reported in the 1912 documents. Thus, settling of the condenser base has occurred. It is hard to say if the leakage was the principal reason of low yield. Unfortunately, no documents concerning the functioning of the condenser are available.

Zibold's attempt inspired the experiments performed in the South of France from 1928 to 1957 by French hydrologists L. Chaptal and M. Goddard, the Belgian engineer A. Knapen (Chaptal, 1932; Jumikis, 1965 and refs. therein). Their installations, which they called "aerial wells", were very massive. The best of them yielded several liters of condensed water a day. After 1957, there were no reported attempts to recover water from vapour despite the attractiveness of this idea.

The main reason for the failures of these constructions may will have been the idea on which their creation was based. F. I. Zibold's ideas on the hydrological cycle were close to Aristotle's conception which was far from the conception of Perrault, Mariotte, and Halley (17th - 18th Cent.), i.e., the modern 
theory. He believed that water forms continuously in the soil, as atmospheric air penetrates the pores and fissures in the ground; cooling condenses water which then accumulates and finally rises to the surface in the form of springs and rivers (Galbrecht, 1987). Hence, the tumuli which are located at the top of the hills may have been mistaken for springs.

\section{Model for condensation in Zibold-type condensers}

Since the 1950s the formation of dew has been investigated both by physicists and by hydrologists. The object of the physical investigation are "breath figures", i.e., the condensation of water on a surface, e.g. on a piece of glass (Beysens et al., 1991). Agrometeorologists are interested in dew formation in nature (Monteith, 1957; Pedro and Gillespie 1982a, b); in particular, Lhomme and Jiminez (1992) were interested in dew on banana plantations because there is a close link between dew and cryptogamic development on the leaves. Environmental scientists study the dew as a source of the acid pollution (Pierson et al., 1986; Janssen et al., 1991).

Dew formation on a surface requires cooling of the latter, generally by thermal irradiation during the night. Alternatively, cooling can occur due to the thermal contact with the ground if the ground is cooler. But at depth the temperature of the soil corresponds to the average daily temperature and remains constant. Thus, this ground level functions like a furnace which heats the ground surface during the night due to the thermal conductivity. An object which is thermally isolated from the ground lacks such a source of heating and thus its temperature can be lower. Hence, engineers of condensers should avoid good thermal contact with the ground. This statement is the first - though not the main - reason of the failure of the condensers in the Southern France which had the concrete shells with the massive foundations (Jumikis, 1965). Zibold's installation consisted of rather large $(15-40 \mathrm{~cm}$ in diameter) pebbles of rounded form. The pebbles thus had weak physical and thermal contact with each other and with the bowl. Thus we can neglect this kind of thermal losses in our rough approximation. Moreover, due to the small thermal conductivity we can assume that temperature varies with time only on a small part of the condenser. Indeed, only 2 or 3 surface-layers of pebbles can perform the irradiation heat exchange with an environment. Also, the fresh humid air cannot penetrate deep into the pile of stones. Therefore we shall consider the working layer to be of the depth $0.3 \mathrm{~m}$ (see Fig. 2). This depth corresponds to three layers of $0.15 \mathrm{~m}$ diameter pebbles out of which the outer layers of Zibold's condenser were made. All this working part as well as the condensed water will be supposed to have a uniform temperature $T_{c}$. We assume also that the pebbles themselves take only a half of the volume of this layer when estimating its mass. The heat balance equation for the condenser is

$$
\frac{d T_{c}}{d t}\left(M c_{c}+m c_{w}\right)=R_{i}+R_{h e}+R_{c o n d}
$$

where the left-hand side represents the rate with which the amount of heat of the condenser changes, $M$ and $m$ are the masses of the working part of the condenser and condensed water respectively, $c_{c}$ and $c_{w}$ are the specific heats of the material of the condenser and water; $t$ is time. Hereafter, SI units are supposed for all the values except the temperature which is expressed in Celsius degrees. The variables in the right-hand side represent the different physical processes due to which the heat energy comes to or leaves the condenser surface: $R_{i}(\mathrm{~W})$ is the irradiation, $R_{h e}(\mathrm{~W})$ is the heat exchange with the surrounding air, $R_{\text {cond }}(\mathrm{W})$ is the energy gain due to the latent heat of the condensation $(L$ per unit mass). Thus

$$
R_{\text {cond }}=L \frac{d m}{d t} .
$$

The heat exchange term can be expressed in the usual form as

$$
R_{h e}=S_{c} a\left(T_{a}-T_{c}\right),
$$

where $a$ is a heat transfer coefficient, $T_{a}$ is the air temperature. $S_{c}$ is the surface area which takes part in heat exchange with the air. Due to the porous structure of the condenser the fresh air penetrates into it and goes out constantly. That is why the value of $S_{c}$ is larger than the external surface of the condenser $S_{i}$ and depends on the wind speed $u$ : the increase of $u$ causes deeper penetration and thus larger value of $S_{c}$. a relates to the width of the aerodynamical boundary air layer and thus depends on $u$ too (see Beysens et al., 1991). The formula (Pedro and Gillespie 1982a)

$$
a=f \sqrt{u / D}
$$


in which the numerical factor $f=4 \mathrm{WK}^{-1} \mathrm{~m}^{-2} \mathrm{~s}^{1 / 2}$ is empirical for the flow parallel to a plane sheet of size $D$. As a rough estimate $D \approx \sqrt{S_{i} / 2}$.

The total irradiation term from Eq.1 can be divided into several parts:

$$
R_{i}=R_{b}+R_{l}+R_{s}-R_{c}
$$

$R_{b}$ is the direct beam irradiation, $R_{l}$ and $R_{s}$ are the long-wave and short-wave parts of the diffuse incoming irradiation and $R_{c}$ is the outgoing irradiation of the condenser which is so important. It can be represented by

$$
R_{c}=S_{i} \varepsilon_{c} \sigma\left(T_{c}+273\right)^{4},
$$

where $\sigma$ is the Stephan-Boltzmann constant and $\varepsilon_{c}$ is the emissivity of the condenser. The longwave and shortwave radiation terms are given by Pedro and Gillespie (1982a) (Below, it is assumed that clouds are absent):

$$
\begin{gathered}
R_{l}=S_{i} \varepsilon_{s} \sigma N\left(T_{a}+273\right)^{4}, \\
R_{s}=S_{i} R_{\text {sol }} \frac{d}{2}\left(1-A^{q}\right) \sin \alpha,
\end{gathered}
$$

where $\varepsilon_{s}$ is the emissivity of the sky, $R_{s o l}$ is the solar constant $\left(1350 \mathrm{~W} / \mathrm{m}^{2}\right), d$ is a short-wave absorptivity of the condenser, $A$ is the atmospheric transmission constant, $q=1 / \sin \alpha$, where $\alpha$ is defined as an angle of elevation of the Sun over the horizon. The numerical coefficient $N$ in (7) depends on the vapour pressure, but the dependence is very weak. For average conditions, $N \approx 0.82$.

It is supposed that night comes when $\alpha$ becomes equal to zero (though it is not exactly so; due to the atmospheric refraction, night comes when $\left.\alpha=-36^{\prime} 36^{\prime \prime}\right)$. $\alpha$ can be estimated by the classical expression (Campbell, 1977)

$$
\sin \alpha=\sin \phi \sin \delta+\cos \phi \cos \delta \cos [\pi(t-12) / 12],
$$

where $t$ is the time of day in hours, $\phi$ is the latitude of the place (for Feodosia $\phi=45^{\circ} 01^{\prime} 45^{\prime \prime}$ ) and $\delta$ is a solar declination.

The estimation of the direct beam irradiation is a slightly more difficult problem. It can be represented by the expression

$$
R_{b}=S_{p} R_{\text {sol }} d A^{q}
$$

where $S_{p}$ is a surface of a geometrical projection of the condenser on the plane perpendicular to the direction of the beams. Since this direction is defined by $\alpha, S_{p}$ is a function of $\alpha$. E. g. for the horizontal plane

$$
S_{p}=S \sin \alpha
$$

for the vertical plane

$$
S_{p}=S \cos \alpha
$$

where $S$ is a surface of the plane. For the plane which has an angle

$$
\alpha_{\max }=\pi / 2-\phi+\delta
$$

with the horizon $S_{p}=0$, since such a plane will be parallel to the solar beams all day long. In all the cases, the planes are supposed to be parallel to the direction East-West. For the truncated cone (see Appendix)

$$
\begin{array}{r}
S_{p}=\left(R^{2}-r^{2}\right) \sin \alpha\left[\left(\tan ^{2} \beta \cot ^{2} \alpha-1\right)^{1 / 2}-\arccos (\tan \alpha \cot \beta)\right] \\
+\pi R^{2} \sin \alpha, \quad 0<\alpha<\beta \\
S_{p}=\pi R^{2} \sin \alpha, \quad \beta<\alpha<\pi / 2
\end{array}
$$

where $R$ and $r$ are the radii of the base and the top of the cone, $\tan \beta=h /(R-r)$ and $h$ is the height of the cone.

The equation for $m$ represents the condensation rate:

$$
\frac{d m}{d t}=\left\{\begin{array}{ll}
S_{c} b\left(p_{v}-p_{c}\left(T_{c}\right)\right), & \text { if } p_{v}>p_{c}\left(T_{c}\right) \\
0, & \text { otherwise }
\end{array} .\right.
$$


Here $p_{v}$ is the partial pressure of the water vapour in the atmosphere which is considered constant during the night. $p_{c}\left(T_{c}\right)$ is the vapour pressure over the condenser at which condensation on its surface begins. $b$ is proportional to $a(4)$ :

$$
b=0.656 a /\left(p c_{a}\right),
$$

where $p$ is the atmospheric pressure and $c_{a}$ is the specific heat of air. This expression as well as the numerical factor comes from the calculations of the vapour transfer coefficient (Pedro and Gillespie 1982a).

Generally speaking, $p_{c}(T)$ does not coincide with the saturation pressure of the water vapour $p_{s}(T)$ and depends on the degree of wetting of the surface by the water which can be characterized by the contact angle (Zhao and Beysens, 1995). For the surface which is incompletely wetted by water (such as for ordinary surfaces which are inevitably coated by some oil or grease) (Beysens et al., 1991) $p_{c}(T) \approx p_{s}(T)$. Consider for the sake of simplicity the case

$$
p_{c}(T)=p_{s}(T)
$$

although in reality $p_{c}(T)<p_{s}(T)$.

Evaporation is neglected (cf. the second option in Eq. 15) and it is assumed that all condensed water flows immediately into a container inside the condenser. The water is removed from the container as soon as condensation stops.

The day of April, 8, 1992 has been chosen for the calculation as the typical of the spring and fall seasons during which the condensation is the largest (Totchilov, 1938). For this day $\delta \approx 7^{\circ}$ (Campbell, 1977); the maximum and minimum air temperatures for that sunny day were $15.2^{\circ} \mathrm{C}$ and $9.5^{\circ} \mathrm{C}$ respectively, the atmospheric pressure was $750 \mathrm{~mm} \mathrm{Hg}$ and the maximal relative humidity for the Tepe-Oba mountain at night was $97 \%$. This corresponds to the dew point temperature $T_{d}=9^{\circ} \mathrm{C}$. We suggest also that the variation of $T_{a}$ is assumed sinusoidal with the period of $24 \mathrm{~h}$ and the maximum at $13 \mathrm{~h} 30^{\prime}$. This delay with respect to the maximum of sun irradiation $(12 \mathrm{~h})$ is usual. The other physical constants for the simulation are given in Table 1.

\begin{tabular}{|c|c|l|}
\hline Parameter & Notation & Value \\
\hline \hline Sky emissivity & $\varepsilon_{s}$ & 0.8 \\
\hline Emissivity of condenser & $\varepsilon_{c}$ & 0.9 \\
\hline $\begin{array}{c}\text { Short-wave absorptivity } \\
\text { of the condenser }\end{array}$ & $d$ & 0.5 (for white beach pebbles) \\
\hline Atmospheric transmission constant & $A$ & 0.84 \\
\hline Specific heat of water & $c_{w}$ & $4.18 \cdot 10^{3}(\mathrm{~J} / \mathrm{kgK})$ \\
\hline Specific heat of stones & $c_{c}$ & $1.09 \cdot 10^{3}(\mathrm{~J} / \mathrm{kgK})$ \\
\hline Specific heat of air & $c_{a}$ & $1.01 \cdot 10^{3}(\mathrm{~J} / \mathrm{kgK})$ \\
\hline Density of stones & - & $2.5 \cdot 10^{3}\left(\mathrm{~kg} / \mathrm{m}^{3}\right)$ \\
\hline Latent heat of condensation & $L$ & $2.26 \cdot 10^{6}(\mathrm{~J} / \mathrm{kg})$ \\
\hline
\end{tabular}

Table 1: Values of physical parameters which are used for the calculations.

\section{Numerical simulation of Zibold's condenser}

Now that all the parameters for the set of Eqs. (1), (15) have been defined, the set can be solved numerically. The conditions

$$
\begin{array}{r}
T_{c}(0 \mathrm{~h})=T_{c}(24 \mathrm{~h}), \\
m(0 \mathrm{~h})=m(24 \mathrm{~h})
\end{array}
$$

have to be specified to provide a periodical (with the period of $24 \mathrm{~h}$ ) change of all the physical values.

The simulation shows that during the day of 09/04/1992 Zibold's condenser would yield 221 l of water. This result is in good agreement with the reported data - 300-360 l. The evolution of all the important parameters is shown in Fig. 4. Condensation stops at about 09:00. The dash-dotted line represents the intensity of the direct beam irradiation of the horizontal plane during the day. The condensation starts 


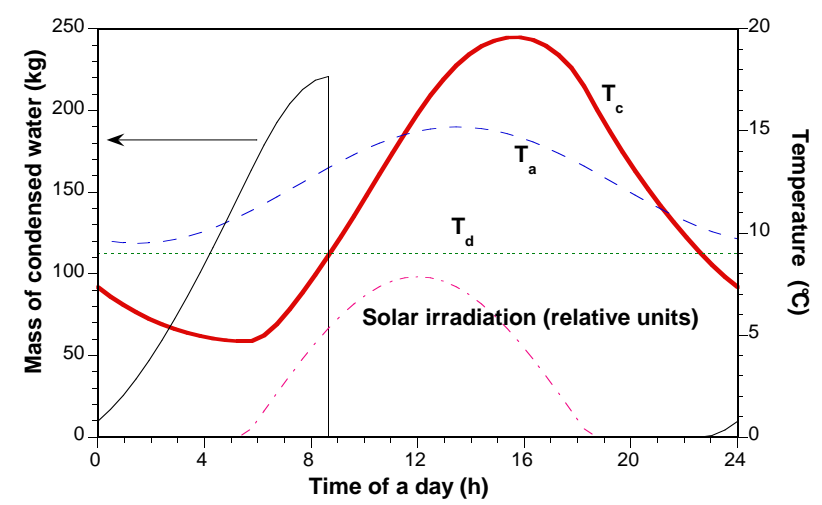

Figure 4: Day evolution of the temperatures of the Zibold condenser $\left(T_{c}\right)$ and the surrounding air $\left(T_{a}\right)$ as well as the mass of condensed water inside the condenser. The evolution of the solar irradiation intensity and dew point temperature $\left(T_{d}\right)$ is shown also. $u=10 \mathrm{~m} / \mathrm{s}$.

\begin{tabular}{|l|l|l|}
\hline Wind speed $(\mathrm{m} / \mathrm{s})$ & $S_{c} / S_{i}$ & Water yield $(\mathrm{l})$ \\
\hline \hline 10 & 2 & 221 \\
\hline 5 & 1.5 & 155 \\
\hline 1 & 1.1 & 61 \\
\hline
\end{tabular}

Table 2: Water yield of Zibold's condenser depending on the wind speed.

4h after the sunset when $T_{c}$ approaches $T_{d}$. Unfortunately there are no other available data concerning the functioning of the condenser and so a more detailed comparison is impossible.

The ratio $S_{c} / S_{i}$ has been assumed to be equal to 2 due to the penetration of the fresh air into the condenser for a rather strong wind $(u=10 \mathrm{~m} / \mathrm{s})$. When the wind is weaker, the fresh humid air penetrates to a smaller depth into the pebble pile and this ratio is smaller. The results for different velocities are presented in Table 2. For the case of Zibold's condenser the water yield is an increasing function of the wind velocity.

\section{Simulation of Zibold-type condensers}

One can distinguish two limiting types of condensers. The first are massive, with $S_{c}>S_{i}$, "Zibold-type condensers". For these it is assumed that $S_{c} / S_{i}=2$ in the following. The representative of the second type is a "grass-like" condenser which is simply a sheet of some light material with both sides working as a condenser. Hence, for these $S_{c}=S_{i}$. The water yield of the first type depends strongly on direct solar irradiation which is determined by the value $S_{p}<S_{i}$, Eq. 10. $S_{p}$, in turn, depends on the shape of the condenser. To generalize the model the shape factor has been excluded from the consideration by defining an effective surface of irradiation $S_{e f f}, S_{p}<S_{e f f}<S_{i}$. $S_{\text {eff } f}$ is the area of a horizontal plane whose total irradiation balance during the day is very close to that of the real condenser. Hence $S_{\text {eff }}$ should be substituted for $S_{i}$ in Eqs. 6-8. Then in (10) we mean under $S_{p}$ the value from (11) where we should substitute $S_{\text {eff }}$ for $S$ also.

For the sake of comparison the same meteorological data and the same values of material constants (Table 1) will be applied as for the case of Zibold's condenser.

The dependence of water yield on the heat capacity $M c_{c}$ of the working layer is shown in Fig. 5. The condenser will work $(m>0)$ if $M c_{c}$ is less than some limiting value which depends on $S_{\text {eff }}$ (this dependence is presented in Fig. 6 as a solid line); the large thermal inertia of the massive working layer may not permit cooling below the dew point temperature during the night (see Fig. 4). The water yield grows very quickly as $M c_{c}$ decreases and soon reaches saturation. The dependence of this value of $M c_{c}$ where saturation is reached (the point where $m$ is less by $5 \%$ than the saturation value) on $S_{\text {eff }}$ is depicted in Fig. 6 as a dashed line. The lower the working mass of the condenser the higher is the water yield.

Saturation takes place due to the interplay of two effects: thermal inertia and irradiation. When $M c_{c}$ is small the temperature evolution will not depend on its value. Then the kinetics is defined by other 


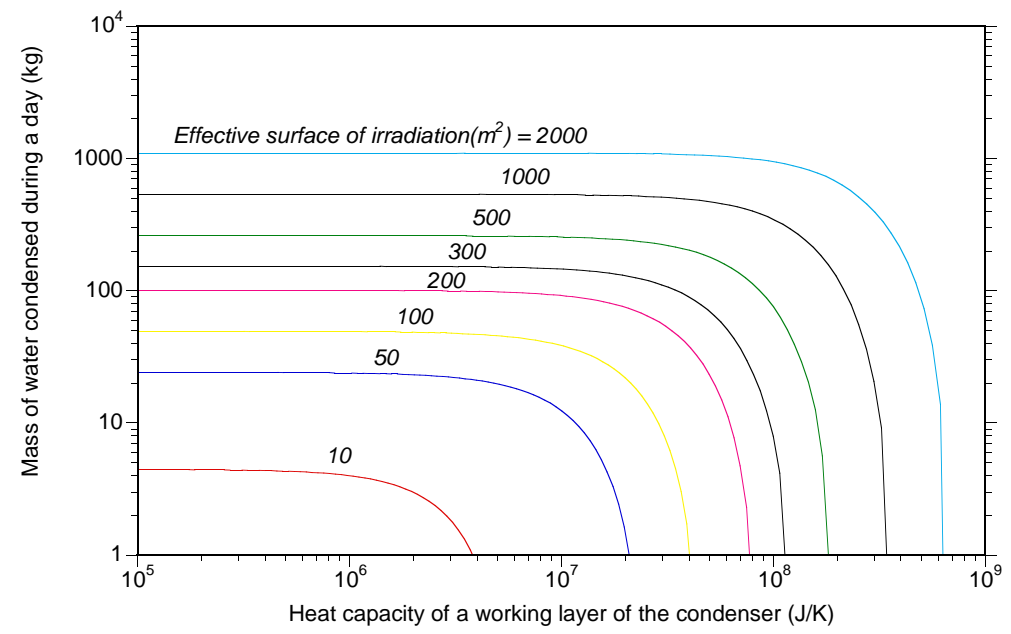

Figure 5: Mass of water condensed during the day versus heat capacity of the working layer of the Zibold-type condenser for $u=10 \mathrm{~m} / \mathrm{s}$.

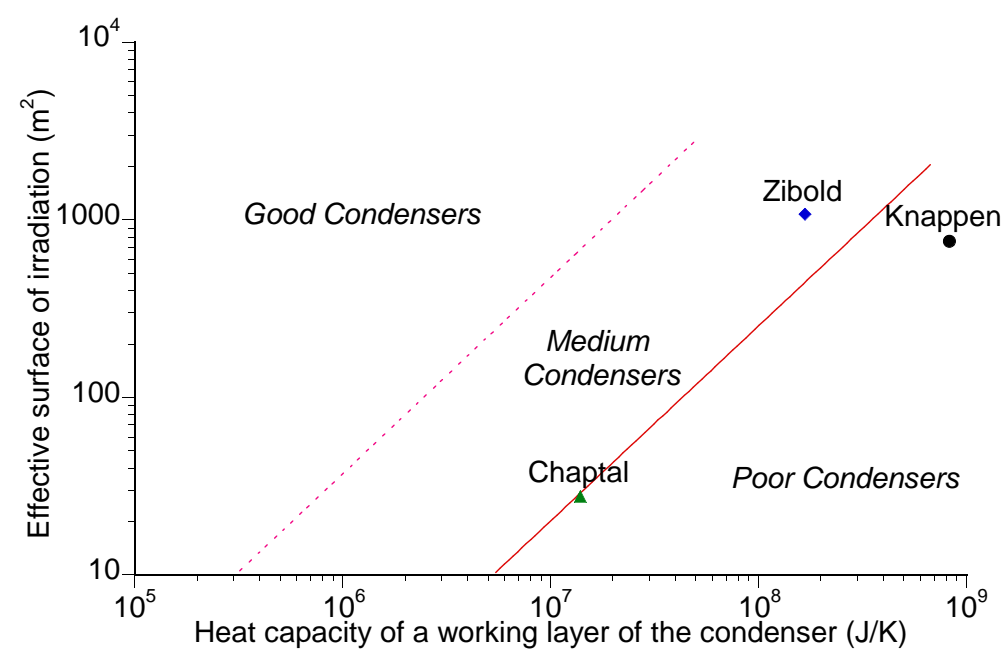

Figure 6: Diagram for the Zibold-type condensers. For explanations see the text. 


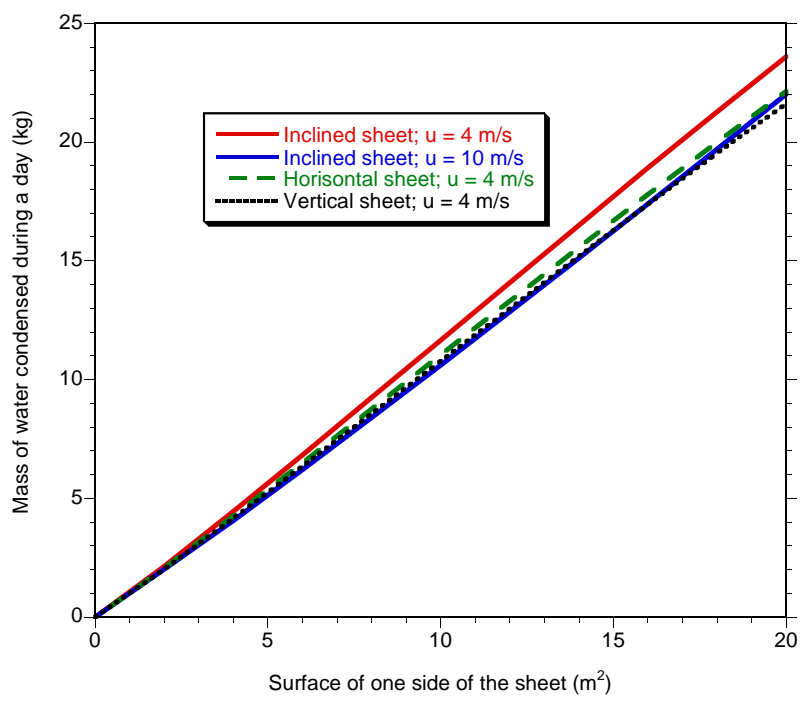

Figure 7: Mass of water condensed during the day versus surface of one side of the polyethylene sheet with the thickness $0.5 \mathrm{~mm}$.

terms in Eq. 1, mostly by the irradiation term. In this case the heat capacity of the condenser can be neglected as occurred in the studies of dew on leaves (Pedro and Gillespie 1982a, 1982b; Lhomme and Jiminez, 1992).

Two lines in Fig. 6 divide the $S_{e f f}-M c_{c}$ plane into three regions of good, medium and poor condensers. This diagram is not universal; its exact shape will depend slightly on the meteorological conditions and the constants of the materials of real structures. Nevertheless, it suffices to compare the quality of the condensers since the parameters $S_{\text {eff }}$ and $M c_{c}$ are the most important. We compare here the quality of Zibold's condenser to the quality of two experimental devices, detailed data on which are available from the literature - Chaptal's first captor in Montpellier and Knappen's aerial well in Trans-en-Provence. The estimated parameters of them are summarized in Table 3.

\begin{tabular}{|l|l|l|l|}
\hline Inventor & $M, 10^{3} \mathrm{~kg}$ & $S_{i}, \mathrm{~m}^{2}$ & $S_{\text {eff }}, \mathrm{m}^{2}$ \\
\hline \hline Zibold & 152 & 854 & 1075 \\
Chaptal & 12.8 & 22 & 27.7 \\
Knappen & 759 & 601 & 757 \\
\hline
\end{tabular}

Table 3: Estimated physical parameters of the different devices.

The corresponding points are depicted in Fig. 6. The positions of the points are in good agreement with the experimental results of the inventors. In fact, both devices were not good condensers giving only several liters of water on the best days. But Chaptal's structure was the more efficient taking into account its smaller size.

It appears that the main fault of the condensers was their large mass.

\section{Simulation of "grass-like" condensers}

The leaves of plants represent nearly ideal dew condensers although their surface is hydrophobic. A good wetting by water is essential to facilitate the condensation with the lower partial vapour pressure $p_{v}$ (Zhao and Beysens, 1995). In addition, the separate drops do not flow quickly from the surface of the leaves so that evaporation of those drops may occur when the sun shines in the morning. A sheet of some polymer material is more suitable for these studies. For a polyethylene sheet with a thickness $0.5 \mathrm{~mm}$, density $0.95 \cdot 10^{3} \mathrm{~kg} / \mathrm{m}^{3}$ and specific heat $c_{c}=1.9 \cdot 10^{3} \mathrm{~J} / \mathrm{kgK}$, the water yield $m$ versus the surface area $S$ of one side of the sheet is presented in Fig. 7. The inertial term in Eq. 1 is small for this case and the temperature follows mainly the change in irradiation.

Three angles of the sheets with the horizon were simulated: $\alpha_{\max }$ defined by (13), $0^{\circ}$ and $90^{\circ}$. In all 
the cases the sheets are supposed to be parallel to the direction East-West. Due to the small thermal inertia, the difference in yield of the water depends only slightly on the angle. But the difference is drastic in the maximal temperature of sheets: for the horizontal or vertical sheets it is about $60^{\circ} \mathrm{C}$, for the inclined one is about $15^{\circ} \mathrm{C}$. The dependence on the wind speed $u$ for this case seems to be unusual - the water yield decreases with the increase of $u$. This is because an increase in air velocity has two consequences: it increases the condensation rate (b, Eq. 16) and it increases the heat exchange with outer air (a, Eq. 4). Because during the most part of the day $T_{c}<T_{a}$ (see Eq. 3), the second effect leads to a heating of the sheet while the first leads to a cooling. For a thin sheet (in contrast to the Zibold-type condenser) the heating appears to be stronger with an increase in $u$.

The small curvature of $m(S)$ lines in Fig. 7 is due to the velocity dependence of the heat transfer coefficient.

\section{Conclusions}

This paper investigated the history and functioning of dew condensers. It is difficult to refute Zibold's hypothesis concerning the Early Greek condensers. This would need extensive excavation work. The Tepe-Oba mountain is fissured by the remains of a sophisticated system of ancient water supply and tubes can be found within hundreds of meters of every mound. But excavations of more than 80 mounds did not reveal any signs of a hydraulic system. On the contrary, tombs were found in each of them. Where water still comes out of the broken water supply, it contains dissolved minerals and thus does not come out of condenser, because condensed water is almost distilled. Moreover, the dry remains of the ancient water tubes are covered (from inside) by a thick layer of mineral deposits. Hence, there was no ancient dew condensers in the surroundings of Feodosia.

We describe the main physical principles of the functioning of dew condensers and suggest a model to simulate them. It turns out that Zibold's condenser was the most successful experimental device among those that ever existed, its yield was of order of 100-200 l of water per day.

We suggest the simple diagram (Fig. 6), which can be used to estimate the quality of the massive ("Zibold-type") condenser and compare it with the other constructions.

The huge mass of the devices was their main fault. It caused the large thermal inertia which did not allow them to cool during the night and thus the conditions for the dew formation were poor. The creators of the massive condensers were not aware that the cooling is, in fact, due to irradiation, and they tried to increase the condensation surface, not the irradiation surface. It is their second fault. Their third fault was a too high thermal contact with the ground. The temperature of a good condenser is lower than ground temperature during the most part of the day. Thus, the ground heats the condenser. The decrease of its quality is a consequence.

Hence the "ideal" condenser should be "grass-like", i. e., a light sheet thermally isolated from the massive parts and the ground. It is very important that its surfaces should be open to let them irradiate the energy into space. It means that nothing that can reflect the infrared irradiation of the condenser, should be placed near its surface and vice-versa, the condenser itself should be placed far enough from such surfaces, e. g. the ground to avoid the "greenhouse" effect. In practice, a vertically placed sheet of some (polymer) film would be suitable. The material of the sheet should be well (ideally completely) wetted by the water to decrease the nucleation barrier. The place of the condenser should be chosen on an open area but where the winds are not strong and dew is frequent (i.e. where humidity is high enough).

A sheet of polyethylene, assuming that there is no evaporation and that all the condensed water flows into a vessel yields approximately $1 \mathrm{l} / \mathrm{m}^{2}$ under the meteorological conditions defined above.

Hence, practical utilization of dew water contained in the air seems possible. Using the present study, engineers of future dew condensers will be able to obtain a volume of very clean water.

\section{Acknowledgments}

The authors thank Mr. Dmitri Novitski, Mayor of Feodosia in Crimea, and Mr. Jean-Pierre Porthelet, Mayor of Trans-en-Provence in France, for their warm welcome. Valuable scientific information was obtained from Dr. Alexander Zibold - F. I. Zibold's grandson, - his wife Katerina (Donetsk) and Prof. V. N. Dublyansky (Simferopol State University). Mrs. A. Wasowicz (Warsaw-Poland) provided 
precious help because of her Early Greek archaeological knowledge in Crimea. The French Embassy in Kiev is thanked for funding expeditions to Feodosia (in 1993 and 1994). The contribution of the European Center for Advanced Studies in Thermodynamics to 1994 mission is also acknowledged. J.-P. Lhomme is thanked for the critical reading of this article. One of the authors (V. N.) would like to thank the collaborators of SPEC Saclay for their kind hospitality.

\section{Appendix}

To obtain Eq. 14, i.e. to find $S_{p}$ for the truncated cone, first find it for a full cone with base radius $R$ and the height $H$ such that

$$
H / R=h /(R-r)=\tan \beta .
$$

Then the truncated cone is a part of the full cone. Assume that $\alpha \leq \pi / 2-$ if not, one should substitute $\pi-\alpha$ for $\alpha$ in the final expression.

To calculate $S_{p}$ for the cone, substitute for the cone the regular pyramid with the same top and with all the base vertices lying on the circle - the base of the cone. Obviously, all the characteristics of the pyramid will tend to those of cone as the number of vertices tends to infinity. Choose the reference point $\mathrm{O}$ of the Cartesian coordinates at the center of the base, the axis OZ as vertical one and axis OX so that Sun will be in XOZ plane. Then the plane defined by the equation

$$
z+x \cot \alpha=0
$$

is perpendicular to the direction of solar beams - it is the projection plane. The sides of the pyramid differs by the polar angle $\gamma$ (in the plane XOY with respect of the point $\mathrm{O}$ and axis OX) of one of the bottom summits. The other one has the angle $\gamma+d \gamma$ where $d \gamma$ tends to zero as number of summits tends to infinity. Then the equation of the geometrical plane, which contains the side as its part, is

$$
x \cos \left(\gamma+\frac{d \gamma}{2}\right)+y \sin \left(\gamma+\frac{d \gamma}{2}\right)+(z-H) \frac{R}{H} \cos \left(\frac{d \gamma}{2}\right)=0
$$

The surface of this side is $d S=\sqrt{H^{2}+R^{2}} R d \gamma / 2$. Now $S_{p}$ is defined as a sum which is transformed into the integral when $d \gamma \rightarrow 0$ :

$$
\begin{aligned}
S_{p} & = \\
& =\sqrt{H^{2}+R^{2}} \frac{R}{2} \int \cos \xi d \gamma
\end{aligned}
$$

$\xi$ is an angle between two inscribed planes, which can be found out of Eqs. A2 and A3 by the straightforward application of the known formula of analytical geometry and is given by

$$
\cos \xi=\sin \beta \cos \alpha \cos \gamma+\cos \beta \sin \alpha .
$$

It follows from Eq. A5 that when $\alpha>\beta$, i.e. when all the surface of the cone is exposed to the solar irradiation, $\xi$ is always less then $\pi / 2$. Thus the integration in (A4) should be performed from 0 to $2 \pi$ yielding

$$
S_{p}=\pi R^{2} \sin \alpha
$$

When $\alpha<\beta$, the sides which has $\xi>\pi / 2$ are not exposed to the solar irradiation. Taking into account that $\xi<\pi / 2$ if $\gamma_{1}<\gamma<2 \pi-\gamma_{1}$, where $\gamma_{1}=\arccos (-\tan \alpha \cot \beta)$, as it follows from Eq. A5, $S_{p}$ should be computed as a sum of two integrals (A4): the first from 0 to $\gamma_{1}$ and the second from $2 \pi-\gamma_{1}$ to $2 \pi$. Hence,

$$
S_{p}=R^{2} \sin \alpha\left[\left(\tan ^{2} \beta \cot ^{2} \alpha-1\right)^{1 / 2}+\pi-\arccos (\tan \alpha \cot \beta)\right]
$$

is valid when $\alpha<\beta$ for the full cone.

Now the cone can be truncated "cutting" its topmost part. Evidently, Eq. A6 is valid for this case when $\alpha>\beta$, since the square of the projection will not depend on inner details (this is also the reason why $S_{p}$ does not depend on the presence of the funnel). To obtain the first part of the Eq. 14 (for $\alpha<\beta$ ), the value of $S_{p}$ for the cone with the base radius $r$ and the same angle $\beta$ (topmost part) has to be subtracted and the square of the projection of the upper base $\pi r^{2} \sin \alpha$ added. 


\section{References}

Anonymous 1915. Proceedings of the inspection of the condenser, which was built in the Feodosian forest. 19.06.1915 (in Russian, manuscript kept in the Feodosian Museum).

Anonymous, 1935. Stenograph of the proceedings of the 1st Conf. on the condensation of the atmospherical water vapour (Aerial well). Moscow-Leningrad, (in Russian, manuscript kept in the Feodosian museum).

Beysens, D., 1993. Rapport de la mission franco-ukranienne effectuée à Féodosia (Crimée, Ukraine) en Septembre-Octobre 1993 (unpublished).

Beysens, D., 1994. Rapport de la mission franco-ukranienne effectuée à Féodosia (Crimée, Ukraine) en Août 1994 (unpublished).

Beysens, D., Gioda, A., Katioushine, E., Milimouk, I., Morel, J.-P. and Nikolayev, V., 1995. Les puits aériens. Submitted to La Recherche.

Beysens, D., Steyer, A., Guenoun, P., Fritter D. and Knobler, C.M., 1991. How does dew form? Phase Transitions, 31: 219-246 and references therein.

Bouloc, J., 1993. De la toile d'araignée... au piège à brouillard. La Houille Blanche, 5: 337-344.

Campbell, G.S., 1977. An introduction to environmental biophysics, Springer Verlag, New-York.

Chaptal, L., 1932. La captation de la vapeur d'eau atmosphérique. La Nature, 60 (2893): 449-454.

Galbrecht, G., 1987. Hydraulic engineering, hydrology and hydraulics in Antiquity. ICID Bull., 36: $1-10$.

Gioda, A. and Acosta Baladón, A.N., 1991. Les puits aériens de Théodosia, de Montpellier et de Trans. Sécheresse, 2: 215-219.

Gioda, A., Acosta Baladón, A., Fontanel, P., Hernández Martin, Z. and Santos, A. 1992. L’arbre fontaine. La Recherche, 23: 1400-1408.

Gioda, A., Beysens, D. and Acosta Baladón, A., 1993a. Dew and atmospheric wells in mediterranean climates. Proc. Symp. on Precipitation and Evaporation, 20-24 September 1993, Bratislava, Slovakia, 3: $279-284$.

Gioda, A., Espejo Guasp, R. and Acosta Baladón, A., 1993b. Fog collectors in the tropics. Proc. Symp. on Precipitation and Evaporation, 20-24 September 1993, Bratislava, Slovakia, 3: 273-278.

Hitier, H., 1925. Condensateurs des vapeurs atmosphériques dans

l'Antiquité. Comptes-Rendus Académie d'Agriculture, Paris: 679-683.

Janssen, L.H.J.M., Römer, F.G. and Kema, N.V., 1991. The frequency and duration of dew occurence over a year. Model results compared with measurements. Tellus, 43B: 408-419.

Jumikis, A.R., 1965. Aerial wells: secondary sources of water. Soil Science, 100: 83-95.

Katiushin, E.A., 1979. Excavations in the surroundings of Feodosia. Arheologitcheskie otkrytija 1978 goda, Nauka, Moscow: 334-339 (in Russian).

L'Hôte, Y., 1987. Rappel de l'historique du concept du cycle de l'eau dans la culture occidentale. IAHS Publ. 164: $37-45$. 
Lhomme, J.-P. and Jimenez O., F., 1992. Estimating dew duration on banana and plantain leaves from standard meteorological observations. Agric. and For. Meteorol., 62: 263-274.

Monteith, J.L., 1957. Dew. Quart. J. Royal Meteorol. Soc., 83: 322-341.

Pedro, M.J. and Gillespie, T.J. 1982a. Estimating dew duration. I. Utilizing micrometeorological data. Agric. Meteorol., 25: 283-296.

Pedro, M.J. and Gillespie, T.J. 1982b. Estimating dew duration. II. Utilizing standard weather station data. Agric. Meteorol., 25: 297-310.

Pierson, W.R., Brachaczek, W.W., Gorse, R.A., Japar, S.M. and Norbeck, J.M., 1986. On the acidity of dew. J. Geophys. Res., 91: 4083-4096.

Schemenauer, R.S. and Cereceda, P., 1991. Fog-water collection in arid coastal locations. Ambio, 20: 303-308.

Totchilov, V.I., 1938. Condensers of Feodosia and the conditions of condensation in the surroundings, Soviet Water Works and Sanitary Engineering, No.1: 61-67 (in Russian).

Zhao, H. and Beysens, D., 1995. From droplet growth to film growth on a heterogeneous surface: condensation associated with a wettability gradient. Langmuir, 11: 627-634.

Zhukov, N.N., 1931. About the ancient hydrotechnical constructions in the surroundings of Feodosia. Collection of the articles on economy, mode of life and history of Feodosian region, Issue 1, Feodosia, (in Russian).

Zibold, F.I., 1905. The role of underground dew in water supply of Feodosia. Trudy opytnyh lesnitchestv, issue III (in Russian, manuscript kept in the Feodosia Museum).

Zibold, F.I., 1907. The experiment of the ancient-Theodosian way of potable water extraction. Lecture given in Feodosia (in Russian, manuscript kept in the Feodosian Museum). 